\title{
Effects of Thymoquinone or Capsaicin against Acrylamide-Induced Testicular Failure in Rats: Impact Oxidative Stress, NF-Kb/P65, and Occludin
}

\author{
Walaa Hasan ${ }^{1}$, ekram abd al haleem ${ }^{1}$, and Hossam Arafa ${ }^{2}$ \\ ${ }^{1} \mathrm{Al}-$ Azhar University \\ ${ }^{2}$ Ahram Canadian University
}

September 5, 2020

\begin{abstract}
Endocrine disrupting effects have become a major issue in the field of environmental toxicology. Due to the testicular toxicity reported for acrylamide and confirmed in our study, and the double jeopardy with its well-documented carcinogenicity following leaching out from overcooked starchy foods, the current study was extended to address the possible protective effects of two nutraceuticals. The present study was designed to assess the possible reproductive toxicity of acrylamide in adult male Swiss albino rats. Also, the work was extended to investigate the potential protective effects of two nutraceuticals namely; thymoquinone (TQ) and capsaicin against acrylamide-induced reproductive toxicity. Sixty male albino rats were allotted into six groups. Group 1: Rats received free tap water and served as control group. Group 2: Rats received acrylamide in a daily dose and served as the model. Group 3: Rats were administered TQ twice weekly. Group 4: Rats were administered capsaicin once daily. Group 5: Rats challenged with acrylamide were administered TQ twice weekly. Group 6: Rats challenged with acrylamide were administered capsaicin once daily. A murine model of acrylamide testicular toxicity was reproduced and was characterized biochemically, morphologically and histologically. Acrylamide increased oxidative stress, expression of testicular $\mathrm{NF}-x \mathrm{~B} / \mathrm{p} 65$, in addition down regulated the expression of occludin that may further account for its testicular toxicity. Both nutraceuticals; TQ and capsaicin have proven more or less efficacy in ameliorating all the toxic insults exerted by acrylamide in the current reproductive toxicity model. Key words: Testicular failure; Thymoquinone; Capsaicin; Acrylamide; NF-KB/P65; Occludin
\end{abstract}

\begin{abstract}
Endocrine disrupting effects have become a major issue in the field of environmental toxicology. Due to the testicular toxicity reported for acrylamide and confirmed in our study, and the double jeopardy with its well-documented carcinogenicity following leaching out from overcooked starchy foods, the current study was extended to address the possible protective effects of two nutraceuticals.

The present study was designed to assess the possible reproductive toxicity of acrylamide in adult male Swiss albino rats. Also, the work was extended to investigate the potential protective effects of two nutraceuticals namely; thymoquinone (TQ) and capsaicin against acrylamide-induced reproductive toxicity.

Sixty male albino rats were allotted into six groups. Group 1: Rats received free tap water and served as control group. Group 2: Rats received acrylamide in a daily dose and served as the model. Group 3: Rats were administered TQ twice weekly. Group 4: Rats were administered capsaicin once daily. Group 5: Rats challenged with acrylamide were administered TQ twice weekly. Group 6: Rats challenged with acrylamide were administered capsaicin once daily.
\end{abstract}


A murine model of acrylamide testicular toxicity was reproduced and was characterized biochemically, morphologically and histologically. Acrylamide increased oxidative stress, expression of testicular NF- $x \mathrm{~B} / \mathrm{p} 65$, in addition down regulated the expression of occludin that may further account for its testicular toxicity. Both nutraceuticals; TQ and capsaicin have proven more or less efficacy in ameliorating all the toxic insults exerted by acrylamide in the current reproductive toxicity model.

Key words: Testicular failure; Thymoquinone; Capsaicin; Acrylamide; NF-KB/P65; Occludin.

\section{Abbreviations}

Thymoquinone (TQ); nuclear factor kappa B (NF-xB/p65); luteinizing hormone (LH); follicle stimulating hormone (FSH); lactate dehydrogenase isoenzyme-X (LDH-X); reduced glutathione (GSH); superoxide dismutase (SOD); thiobarbituric acid reactive substances (TBARS); catalase (CAT); malondialdehyde (MDA).

\section{Introduction}

Acrylamide is a versatile organic compound that finds its way into many products in our everyday life. Acrylamide has been found to occur in many cooked starchy foods and is of concern as a possible carcinogen. Acrylamide was accidentally discovered in foods in April 2002 by scientists in Sweden when they found the chemical in starchy foods, such as potato chips, French fries, and bread that had been heated above $120^{\circ}$ (Tareke, Rydberg, Karlsson, Eriksson, \& Törnqvist, 2002). Apart from its possible carcinogenic effects, acrylamide has shown reproductive toxicity in rats (Parzefall, 2008) and(Abdel-Fattah, Matsumoto, \& Watanabe, 2000). However, the precise mechanism(s) are not fully explored.

Nutraceutical, a portmanteau of the words "nutrition" and "pharmaceutical", is a food or food product that reportedly provides health and medical benefits, including the prevention and treatment of diseases (Yadav, PATIL, \& Gupta, 2013). Such products may range from isolated nutrients, dietary supplements and specific diets to genetically engineered foods, herbal products, and processed foods such as cereals, soups, and beverages (Parvez, Malik, Ah Kang, \& Kim, 2006). They provide health and medical benefits that delay, prevent and treat chronic inflammatory diseases due to the presence of the phytochemicals. Their beneficial effects reside for the most part on their anti-oxidative role that can reduce the level of ROS and free radicals, beside its powerful anti-inflammatory actions (Pyun, Kim, Han, Hong, \& Lee, 2014).

Thymoquinone (TQ) is a phytochemical nutraceutical found in the plant Nigella sativa. It has antioxidant effects, and has been shown to protect against heart, liver and kidney damage in animal studies, as well as having possible anti-cancer effects (B Aggarwal et al., 2011). It also has analgesic (Abdel-Fattah et al., 2000) (and anticonvulsant effects in animal models (Hosseinzadeh \& Parvardeh, 2004).

Capsaicin is the main capsaicinoid in chili peppers. Capsaicin is currently used in topical ointments, as well as a high-dose dermal patch, to relieve the pain of peripheral neuropathy such as post-herpetic neuralgia caused by shingles (Chhabra, Aseri, Goyal, \& Sankhla, 2012). Many pharmacological studies have used capsaicin as a tool to activate many physiological systems, with an emphasis on pain research, but also including functions such as the cardiovascular system, the respiratory system, and the urinary tract (O'Neill et al., 2012).

Taken together, the current study has been conducted to address the possible protective effects of two nutraceuticals, well known for their potential anti-oxidant and anti-inflammatory effects namely; TQ and capsaicin in acrylamide-challenged male rats.

The main objectives of the current study; to identify the possible mechanisms whereby acrylamide may induce damage in testicular and edpididymal tissues following the toxic insult with the xenobiotic. In addition, address the potential chemopreventive effects of the test compounds under investigation, and the possible underlying mechanism(s) with special emphasis on occludin as a tight junction protein crucial for the integrity of the basement membrane of the blood testes barrier, and nuclear factor kappa B (NF- $\chi \mathrm{B} / \mathrm{P} 65)$ as a marker of inflammation that would ultimately signal an adverse change to spermatogenesis after toxic insult. 


\section{Materials and Methods}

\section{Design of the Work}

Herein, sixty male albino rats were allotted into six groups, (ten rats each).

Group 1: Rats received free tap water orally for 8 weeks and served as control group.

Group 2: Rats received acrylamide in a daily dose of (35 mg $/ \mathrm{kg}$ ) (Friedman, 2003) for 8 weeks. Acrylamide was dissolved in drinking water, and the estimated daily intake of water was about $10 \mathrm{mg} / 100 \mathrm{~g}$ rat as previously reported (Slone et al., 2012); this group served as the model.

Group 3: Rats were administered TQ dissolved in $10 \%$ DMSO and water (15 mg $/ \mathrm{kg}$, IP) (Tavakkoli, Ahmadi, Razavi, \& Hosseinzadeh, 2017), twice weekly for 8 weeks.

Group 4: Rats were administered capsaicin dissolved in $10 \%$ DMSO and water (10 mg/kg, PO) once daily for 8 weeks (Shimeda et al., 2005).

Group 5: Rats challenged with acrylamide were administered TQ dissolved in 10\% DMSO and water (15 $\mathrm{mg} / \mathrm{kg}, \mathrm{IP}$ ) twice weekly for 8 weeks.

Group 6: Rats challenged with acrylamide were administered by oral gavage capsaicin $(10 \mathrm{mg} / \mathrm{kg})$ dissolved in $10 \%$ DMSO and water once daily for 8 weeks.

Twenty-four hours after the last treatment, retro-orbital blood samples were withdrawn under light ether anesthesia using heparinized microcapillaries (Optilab, Berlin, Germany). The serum was separated by centrifugation at $4000 \mathrm{rpm}$ at $4^{\circ} \mathrm{C}$ using cooling centrifuge (Haereus Biofuge, Berlin, Germany). Serum was then stored at $-70^{\circ} \mathrm{C}$ until use for the assessment of biochemical parameters (testosterone, follicle stimulating hormone (FSH) and luteinizing hormone ( $\mathrm{LH})$ ). After terminal bleeding, the animals were euthanized by cervical dislocation and their testes as well as cauda epididymides were dissected out, washed with saline, blotted dry on filter papers, and weighed to determine the relative testicular body weight.

The cauda epididymides were processed for gaining the seminal fluid. The fluid was used to assess sperm count and motility as well as the incidence of head and tail abnormalities. Right testes were homogenized in ice-cold $0.15 \mathrm{M} \mathrm{KC1}(\mathrm{w} / \mathrm{v})$ and the homogenate was used for investigation of the following biochemical parameters. Some of the left testes were preserved in Boiun's solution and used thereafter for histopathological investigation. Histological specimens were used for immunohistochemical localization of $\mathrm{NF}-\varkappa \mathrm{B} / \mathrm{p} 65$ and immunofluorescent detection of occludin.

\section{Animals}

Sixty male Swiss albino rats weighing (150-200) g were used. The animals were housed in the animal facility of the Faculty of Medicine, Ain Shams University. The rats were kept under standard conditions of temperature $\left(21^{\circ} \mathrm{C} \pm 0.5\right)$ and relative humidity $(55 \pm 1)$ with 12-light/12-dark cycle. They were fed with standard diet pellets (El-Nasr Chemical Company, Abou-Zaabal, Cairo, Egypt). Food and water were given ad libitum. The experimental protocol utilized in this examination was endorsed by the Animal Ethics Committee (No. 70/2016) of the Faculty of Pharmacy, Al-Azhar University, Egypt.

\section{Chemicals and Reagents}

Acrylamide : It was purchased from Sigma-Aldrich (St. Louis, MO, USA) as white crystalline powder. It is freely soluble in water, ethanol, ether and chloroform. It has a molecular formula of $\mathbf{C}_{\mathbf{3}} \mathbf{H}{ }_{5} \mathbf{N O}$. Its IUPAC name is prop-2-enamide.

Capsaicin: It was obtained from Sigma-Aldrich (St. Louis, MO, USA) as white crystals with a molecular formula of $\mathbf{C}_{\mathbf{1 8}} \mathbf{H}_{\mathbf{2}} \mathbf{N O}_{\mathbf{3}}$. Capsaicin is soluble in organic solvents such as ethanol, DMSO, and dimethyl formamide. The solubility of capsaicin in these solvents is at least $30 \mathrm{mg} / \mathrm{ml}$. 
TQ: It was obtained from Sigma-Aldrich (St. Louis, MO, USA) as brown crystals with a molecular formula of $\mathbf{C}_{10} \mathbf{H}_{12} \mathbf{O}_{2}$. TQ is soluble in organic solvents such as ethanol, DMSO, and dimethyl formamide. The solubility of TQ in ethanol and DMF is approximately $16 \mathrm{mg} / \mathrm{ml}$ and in DMSO it is approximately 14 $\mathrm{mg} / \mathrm{ml}$.

\section{Methods}

\section{Assessment of relative weight of the testes}

After the animals have been weighed and euthanized by cervical dislocation, right and left testes as well as cauda epididymes were dissected out placed in normal saline, washed out well and blotted dry on filter paper. The two testes were weighed for calculation of their relative testes/body weight.

\section{Determination of sperm parameters}

\section{Assessment of sperm count and motility}

Assessment of sperm count and motility was achieved according to the routine of Freund and Carol(Freund \& Carol, 1964). The two cauda epididymis from each rat were situated in $2 \mathrm{ml}$ of warmed (37 C) Earle's buffer. Sperm count and motility were inspected using hemocytometer and the light microscope as expressed by Hoppe and Pitts (Hoppe \& Pitts, 1973).

\section{Assessment of sperm head and tail abnormalities}

The sperm abnormality test is an in vivo assay used for determination of any agent capable of causing an increase in the incidence of sperm with morphologically abnormal head and tail shapes in male animals. The assessment of sperm head and tail abnormalities was made according to Wyrobek et al .

(Wyrobek et al., 1983).

Investigation of serum biochemical parameters

\section{Determination of serum testosterone concentration}

The DRG Testosterone ELISA Kit is a solid phase enzyme-linked immunosorbent assay (ELISA), based on the principle of competitive binding. The microtiter wells are coated with an antibody directed towards a unique antigenic site on the testosterone molecule. Endogenous testosterone of the sample competes with the testosterone horseradish peroxidase conjugate for binding to the coated antibody. After incubation for 15 minutes, the unbound conjugate is washed off. The amount of bound testosterone horseradish peroxidase conjugate is reversely proportional to the concentration of testosterone in the sample. After addition of the substrate solution, the intensity of the developed color is reversely proportional to the concentration of testosterone in the given sample (Tietz, 1986).

\section{Determination of serum follicle stimulating hormone (FSH) level}

Biotin-conjugated anti-FSH and standard or sample is incubated in monoclonal anti-FSH antibody-coated wells. After $15^{\sim} 18$ hours incubation and washing, HRP (horseradish peroxidase)-conjugated avidin is added and incubated for 30 minutes. After washing, HRP-complex remaining in wells are reacted with a chromogenic substrate (TMB) for 30 minutes, and reaction is stopped by addition of acidic solution, and absorbance of yellow product is measured spectrophotometrically at $450 \mathrm{~nm}$ (sub-wavelength is $620 \mathrm{~nm}$ ). The absorbance is nearly proportional to FSH concentration. The standard curve is prepared by plotting absorbance against standard FSH concentrations (Markkula, Hämäläinen, Loune, \& Huhtaniemi, 1995).

\section{Determination of serum luteinizing hormone (LH) level}

Standards or samples are incubated in monoclonal anti-LH $\beta$ antibody coated wells to capture LH. After 2 hours' incubation and washing, biotinylated anti-LH $\alpha$ antibody is added and incubated further for 1 
hour to bind with captured LH. After washing, HRP (horseradish peroxidase)-conjugated streptavidin is added and incubated for 30 minutes. After washing, HRP-complex remaining in wells is reacted with a chromogen (TMB) for 20 minutes, and reaction is stopped by addition of acidic solution, and absorbance of yellow product is measured spectrophotometrically at $450 \mathrm{~nm}$. The absorbance is proportional to $\mathrm{LH}$ concentration. The standard curve is prepared by plotting absorbance against standard LH concentrations (Pakarainen et al., 2007).

\section{Investigation of tissue biochemical parameters}

\section{Determination of lactate dehydrogenase isoenzyme-X (LDH-X) isoenzyme activity}

LDH-X activity is an indicator of the testicular function (Foster, Blackburn, Moore, \& Lloyd, 1986), and can be analyzed spectrophotometrically at $340 \mathrm{~nm}$ by determination of NADH formation using DL- $\alpha$ Hydroxycaproic Acid (LDH-X isoenzyme-specific substrate (Cheever, Weigel, Richards, Lal, \& Plotnick, 1985).

\section{Determination of testicular reduced glutathione (GSH) content}

GSH content was determined using ElIman's reagent according to the method earlier described by Ellman et al.(Ellman, 1959).

Determination of thiobarbituric acid reactive substances (TBARS) contents calculated as malondialdehyde (MDA)

Colorimetric determination of TBARS [calculated as MDA content] is based on the reaction of one molecule of MDA with two molecules of thiobarbituric acid at low $\mathrm{pH}(2-3)$, and a temperature of $95^{\circ} \mathrm{C}$ for 45 min. The resultant pink color was extracted with n-butanol, and the absorbance was determined at $535 \mathrm{~nm}$ and $520 \mathrm{~nm}$ spectrophotometrically (Uchiyama \& Mihara, 1978).

\section{Determination of superoxide dismutase (SOD) activity}

The activity of SOD was determined depending on the inhibition of pyrogallol auto-oxidation by SOD. The inhibition is directly proportional to the activity of SOD in the tested sample (Marklund, 1985).

\section{Determination of catalase (CAT) activity}

CAT activity was estimated in the testicular tissues depending on the disappearance of hydrogen peroxide $\left(\mathrm{H}_{2} \mathrm{O}_{2}\right)$ by the action of the enzyme that is measured spectrophotometrically at $240 \mathrm{~nm}$ (Greenwald, 1985).

\section{Histopathological examination of the testes}

Necropsy samples were taken from the testes of rats in the different groups of the work and fixed in Bouin's solution for twenty-four hours. Washing was done using tap water then serial dilutions of alcohol (methyl, ethyl and absolute ethyl) were used for dehydration. Specimens were cleared in xylene and embedded in paraffin at 56 degree in hot air oven for twenty-four hours. Paraffin bees wax tissue blocks were prepared for sectioning at 4 microns by microtome. The obtained tissue sections were collected on glass slides, deparffinized and stained by hematoxylin and eosin stains (Banchrof, Steven, \& Turner, 1996) for histopathological examination through the light microscope.

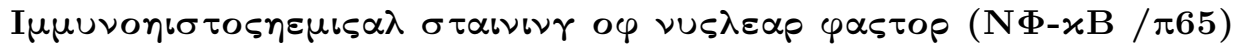

For immunohistochemical evaluation, histological sections were incubated at $60^{\circ} \mathrm{C}$ overnight, and then dewaxed in xylene for $30 \mathrm{~min}$. After rehydrating in a decreasing series of ethanol, sections were washed with distilled water and Phosphate buffered saline (PBS) for $10 \mathrm{~min}$. Sections were then treated with $2 \%$ trypsin in $50 \mathrm{mM}$ Tris buffer $(\mathrm{pH} 7.5)$ at $37^{\circ} \mathrm{C}$ for $15 \mathrm{~min}$ and washed with PBS. Sections were delineated with a Dako pen (Dako, Glostrup, Denmark) and incubated in a solution of $3 \% \mathrm{H}_{2} \mathrm{O}_{2}$ for 15 min to inhibit endogenous peroxidase activity. Then, sections were incubated with NF-kB/p65 monoclonal antibody. Immunohistochemistry was performed using the standard method (avidin biotin peroxidase) according to

Bratthauer(Bratthauer, 2010). 


\section{Immunofluorescence detection of occludin in rat testicular tissue}

Immunofluorescence is an antigen-antibody reaction in which the antibodies are labeled with fluorescent dyes and the formed antigen-antibody complex is visualized using fluorescent microscope. Two types of immunofluorescence assay are present, direct assay in which the antigen is allowed to bind with specific (primary) antibody that is labeled with a fluorescent dye, while in the indirect assay; the antigen is allowed to react with unlabeled primary antibody which in turn reacts with a secondary labeled antibody. This secondary antibody binds to Fc portion of the primary antibody. On washing, the unbound antibodies get washed off, while the bound antibodies remain (Odell \& Cook, 2013). In the present study, the indirect immunofluorescence assay was adopted.

\section{Statistical analysis}

All statistical analyses were achieved using GraphPad InStat, software program (version 5, Philadelphia, USA). Data were presented as means \pm SE. Multiple comparisons were done using ANOVA followed by Tukey test as post-hoc test. $\mathrm{P}$ value $<0.05$ was used as a criterion for significance.

Results

Effects of thymoquinone or capsaicin on relative testes weight, sperm count, motility and morphology head and tail abnormalities of sperms in acrylamide-challenged rats

Effects of TQ or capsaicin on relative testes weight in acrylamide-challenged rats

Challenging rats with acrylamide, significantly decreased the relative weight of testes by about $35 \%$ compared to control group. Co-treatment with either TQ or capsaicin ahead of acrylamide challenge significantly increased relative testes weight by about $45 \%$ compared to the group that received acrylamide only (Table 1).

Effects of thymoquinone or capsaicin on sperm count in acrylamide-challenged rats

Treatment with acrylamide resulted in marked decrease in the normal sperm count by about $42 \%$ compared to control group. However, concurrent administration of TQ or capsaicin to acrylamide-treated rats showed significant increases in sperm counts amounted to $65 \%$ and $89 \%$, respectively compared to animals that received acrylamide alone(Table $\mathbf{1}$ ) .

\section{Effects of thymoquinone or capsaicin on sperm motility in acrylamide-challenged rats}

Acrylamide, however, provoked marked decrease in the normal sperm motility by about $79 \%$ compared to the control group. Nevertheless, concomitant administration of either TQ or capsaicin to acrylamide-challenged rats improved the sperm motility by about $380 \%$ and $357 \%$, respectively compared to rats that received acrylamide alone in tap water. Apparently, sperm motility was restored almost back to normal function (Table 1) .

Effects of thymoquinone or capsaicin on sperm head abnormalities in acrylamide-challenged rats

However, eight-week exposure to acrylamide resulted in significantly increased percentage of head abnormalities amounted to $136 \%$ compared to control group. Also, concurrent administration of TQ or capsaicin to acrylamide-challenged rats significantly decreased the percentages of sperm head abnormalities by about $54 \%$ and $40 \%$, respectively compared to the animals treated with acrylamide alone (Table 1) .

Effects of thymoquinone or capsaicin on sperm tail abnormalities in acrylamide-challenged rats

Challenging animals with acrylamide for 8 weeks resulted in significantly increased percentage of sperm tail abnormalities by about $229 \%$ compared to control group. Also, concomitant treatment with TQ or capsaicin of animals kept on acrylamide significantly decreased the percentages of sperm tail abnormalities by about $60 \%$ and $55 \%$, respectively compared to animals challenged with acrylamide alone(Table 1) . 
Effects of thymoquinone or capsaicin on serum sex hormones levels in acrylamide challenged rats

Effects of thymoquinone or capsaicin on serum testosterone level in acrylamide challenged rats

Challenging animals with acrylamide induced marked reduction in the androgen level by about $52 \%$ compared to the control group. Concurrent administration of TQ or capsaicin to acrylamide-challenged rats resulted in significant increases in serum levels of testosterone amounted to $98 \%$ and $91 \%$, respectively compared to acrylamide-treated animals(Table 2) .

Effects of thymoquinone or capsaicin on Serum follicle stimulating hormone (FSH) level in acrylamide challenged rats

Challenging animals with acrylamide dramatically decreased serum FSH level by about $66 \%$ compared to control rats. Concomitant administration of either TQ or capsaicin resulted in marked increases in serum FSH levels amounted to $176 \%$ and $116 \%$, respectively compared to animals that received acrylamide alone. Further, combination of TQ with acrylamide elevated the serum FSH level by about $28 \%$ compared to the group administered capsaicin and acrylamide (Table $\mathbf{2}$ ).

Effects of thymoquinone or capsaicin on serum luteinizing hormone (LH) Level in acrylamide challenged rats

Animals kept on acrylamide showed marked nadir in serum level of LH amounted to $63 \%$ compared to control animals. Concurrent administration of either TQ or capsaicin to animals challenged with acrylamide exhibited apparent increases in serum LH levels amounted to $95 \%$ and $78 \%$, respectively compared to rats treated with acrylamide alone(Table 2) .

Effects of thymoquinone or capsaicin on testicular lactate dehydrogenase isoenzyme-X (LDH$\mathrm{X})$ activity in acrylamide-challenged rats

Acrylamide, however, exhibited apparent decrease in LDH-X activity amounted to $48 \%$ compared to control animals. Concurrent administration with TQ to rats challenged with acrylamide showed significant increase in LDH-X activity amounted to about $31 \%$ compared to animals treated with acrylamide alone. Capsaicin had no effect on LDH-X activity when given to animals kept on acrylamide compared to the group that received acrylamide alone (Figure $\mathbf{1})$.

Effects of thymoquinone or capsaicin on antioxidants parameters level in acrylamide challenged rats

Effects of thymoquinone or capsaicin on testicular reduced glutathione (GSH) content in acrylamide-challenged rats

Acrylamide-treated animals exhibited marked reduction in testicular GSH content by $71 \%$ compared to control animals. Concomitant treatment of acrylamide-challenged rats with either TQ or capsaicin resulted in significant increases in testicular GSH contents amounted to $111 \%$ and $70 \%$, respectively compared to the group that received acrylamide alone. Further, the animals that received capsaicin and acrylamide exhibited significant decrease in testicular GSH content amounted to $40 \%$ compared to those administered a combo of TQ and acrylamide (Table 3) .

Effects of thymoquinone or capsaicin on testicular malondialdehyde (MDA) content in acrylamide-challenged rats

Acrylamide, drastically increased testicular MDA by more than 4-fold (418\%) compared to control animals. Administration of either TQ or capsaicin to acrylamide-challenged rats significantly reduced testicular contents by $58 \%$ and $40 \%$, respectively compared to animals that received acrylamide alone. There was also significant elevation in testicular MDA level amounted to $43 \%$ following co-administration of capsaicin and acrylamide compared to the group that received TQ and acrylamide (Table 3) . 
Effects of treatment regimens on testicular superoxide dismutase (SOD) activity in acrylamide challenged rats

Acrylamide, however, decreased the enzymatic activity by $91 \%$ compared to control rats. Co-administration of either TQ or capsaicin to animals that received acrylamide apparently increased SOD activities by 266 and $169 \%$, respectively compared to the group that received acrylamide alone. Besides, there was a significant decrease in SOD activity amounted to $27 \%$ following the combination regimen of capsaicin and acrylamide compared to TQ and acrylamide group (Table 3) .

Effects of treatment regimens on testicular catalase (CAT) activity in acrylamide-challenged rats

Acrylamide, however, induced dramatic decrease in the enzymatic activity amounted to $83 \%$ compared to control rats. Concurrent administration of either TQ or capsaicin to the animals given acrylamide resulted in notable increases in the enzymatic activities in testicular tissue amounted to about $236 \%$ and $198 \%$, respectively compared to the group that received acrylamide alone.

Further, the group co-treated with capsaicin and acrylamide exhibited lower but significant decrease in CAT activity by about $11 \%$ compared to the animals that received TQ and acrylamide (Table 3 ) .

Effects of treatment regimens on histopathological examination of the testicular tissue specimens

The results are presented as a photomicrograph in figure (2) and severity of histopathological alterations in testicular tissue specimens of different experimental groups was shown.

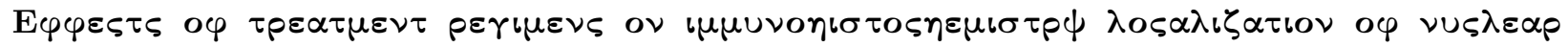

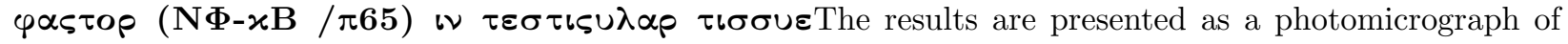
testicular tissue specimens in figure (3), and intensity of immuno-histological reactions of NF- $\chi \mathrm{B} / \mathrm{p} 65$ in of testicular tissue specimens of different experimental groups was shown in table (4).

Acrylamide induced diffuse strong positive immunoreaction of NF- $\chi \mathrm{B} / \mathrm{p} 65$ (brown color) in rat testicular tissue. There was dramatic increase in reciprocal intensity amounted to 37 -fold compared to normal tissue. Tissue sections obtained from the group co-treated with TQ and acrylamide demonstrated that most of the seminiferous tubules were intact with complete spermatogenic series, and showed weak positive immunoreaction for NF- $\chi \mathrm{B} / \mathrm{p} 65$. Reciprocal intensity as a measure of the degree of staining was significantly reduced by about $51 \%$ compared to acrylamide-treated animals. Nevertheless, the reciprocal activity was still higher than the normal testicular tissue by 18-fold (Figure 3 and Table 4 ).

Likewise, concurrent administration of capsaicin and acrylamide exhibited less immunoreactivitiy than animals challenged with acrylamide alone. Besides, the reciprocal intensity was significantly reduced by $47 \%$ compared to that of acrylamide group. Further, there was no significant difference in the expression profile of NF- $x$ B/p65 following the combination modalities that incorporated acrylamide with either TQ or capsaicin (Figure 3 and Table 4 ).

Effects of treatment regimens on immunoflorescence detection of occludin in testicular tissue

The results are presented as a photomicrograph of testicular tissue specimens in figure (4), and fluorescence intensity of occludin in of testicular tissue specimens of different experimental groups were shown in table (4).

Following acrylamide challenge, there was a marked nadir in the expression of the junctional protein as shown from the apparent decrease in the green fluorescence intensity amounted to $55 \%$ compared to control animals associated with loss of most of the integrity of basement membrane surrounding the seminiferous tubules. Administration of TQ to acrylamide-treated rats significantly increased the expression of interstitial occludin by about $99 \%$ compared to acrylamide-challenged animals, and almost restored it to the normal expression pattern (Figure 4 and Table 4 ). 
By the same token, concomitant administration of capsaicin with acrylamide resulted in notable increase in the expression of occludin at the basement membrane by about $110 \%$ compared to rats that received acrylamide alone, and almost brought back the junctional protein expression to the normal level (Figure 4 and Table 4 ).

\section{Discussion}

Acrylamide is one of the most important agents that attracted considerable attention of the scientific community and general public due to its extensive presence in food and variety of applications (Kuorwel, Lumori, \& Andrew, 2018). Mammalian studies have provided a lot of evidence that acrylamide induced a range of reproductive effects in males including disruption of reproductive development, alteration of steroid hormone balance, testicular lesions and atrophy, disruption of spermatogenesis as well as infertility(Xie et al., 2017).

In the present study, repeated administration of acrylamide to adult rats caused reduction in the relative testicular weight and marked deterioration of the histological tissue architecture. As regards sperm morphology, acrylamide apparently decreased sperm count and motility meanwhile it increased significantly the incidence of sperm head and tail abnormalities. Though the mechanisms whereby acrylamide induced such toxic effects on male rat reproductive system, an array of mechanistic approaches have been postulated. Acrylamide effect on rodent reproductive performance was discussed earlier in a review by Tyl and Friedman(Tyl \& Friedman, 2003). It was concluded that acrylamide may induce such toxicity through its metabolite; glycidamide binding to spermatid protamines, causing dominant lethality and effects on sperm morphology; and acrylamide binding to motor proteins, causing distal axonopathy, including hindlimb weakness/paresis, and effects on mounting, sperm motility, and intromission (Aras, Cakar, Ozkavukcu, Can, \& Cinar, 2017).

It is known that sperm motility is ultimately related to healthy mitochondria and therefore, mitochondrial damage might result in reduction of sperm movement. This mitochondrial inhibitory potential provides a possible explanation for poor sperm motility in rats exposed to acrylamide (Mu et al., 2017).

Indeed several recent studies indicated that flavonoids had the protective property against acrylamideinduced oxidative stress and cell apoptosis in vivo and in vitro(Zhang et al., 2017) and(He et al., 2017). However, the protective effects of functional food and nutraceuticals on acrylamide-induced toxicity merit further investigation. TQ administered to acrylamide-challenged rats improved sperm morphology as manifested by increased sperm count and motility. It also increased the relative testes weight and decreased sperm head and tail abnormalities. Histological alterations induced in testicular tissues were also abrogated by the polyphenolic compound. Similar results were reported for TQ following other toxic chemicals.

Generally speaking, it is important to say that many studies elucidated the protective effects of TQ against the reproductive toxicities induced by different agents; such as diesel exhaust particles (Tavakkoli et al., 2017) and streptozotocin (Atta et al., 2018). TQ was able to ameliorate the deleterious effects of cadmium chloride on sperm motility, count and abnormalities in rats (Sayed, Hassanein, \& Senosy, 2014).Mabrouk and Ben Cheikh (Mabrouk \& Ben Cheikh, 2016) reported that TQ improved spermatogenic function by increasing epididymal sperm count in rats exposed to lead acetate. TQ also significantly boosted motility, morphology, count, viability of sperm cells, germinal thickness in morphine-treated mice (Salahshoor, Haghjoo, Roshankhah, Makalani, \& Jalili, 2018).

In our results acrylamide group co-treated with capsaicin shows increase in sperms count and motility and decrease in sperm head and tail abnormalities, this is paralyzed with a previous study which shows that in cocks fed with a diet containing $1 \%$ red hot pepper $(10 \mathrm{~g} / \mathrm{kg}$ diet $)$, their body weight gain decreased, whereas the testes weight, length, width and wall thickness of tubules seminiferous contortus increased, and the completion of spermatogenic cell serial formation took place earlier when compared to control group (Özer, Zik, Erdost, \& ÖZFILIZ, 2006).

Capsaicin tested as a second nutraceutical in the present work has shown remarkable protective effects on both spermatogenic and steroidogeneic functions. It increased sperm count and motility and further 
decreased sperm head and tail abnormalities. Also, the histopathological alterations induced by acrylamide were mitigated. Similar results were previously reported. Park et al. (Park et al., 2017) documented that the pungent principle or red pepper; capsaicin was able to protect against testicular injuries induced by transient scrotal hyperthermia. Low testicular weight, severe vacuolization of seminiferous tubules followed by loss of spermatogenic cells, and appearance of multinucleated giant cells were all mitigated.

Acrylamide can affect sperm parameters as well as sperm chromatin condensation and DNA integrity in mice. These abnormalities may be related to the reduction in blood testosterone. (Pourentezari et al., 2014). Interestingly, acrylamide notably decreased the serum levels of sex hormones; testosterone, LH and FSH. This coping with many previous studies; that documented deterioration in the male sex hormones following exposure to the endocrine disruptor; acrylamide (Erdemli et al., 2019). FSH, LH, and testosterone are known to regulate and sustain testicular function. The main function of FSH is to regulate and promote the spermatogenesis in males. Needless to say that testosterone is the critical hormone which maintains spermatogenesis in the testis (Xiao, Nabi, Yang, Hao, \& Wang, 2018). Evidence for the critical role of the LH-testosterone signaling pathway in initiating and maintaining spermatogenesis has been obtained from several animal models and experimental approaches (O'Donnell, Meachem, Stanton, \& McLachlan, 2006). $\mathrm{LH} /$ testosterone and FSH are the pivotal endocrine factors controlling testicular functions and they are crucial for spermatogenesis (Ramaswamy \& Weinbauer, 2014).

TQ did not only improve the spermatogenic function but also boosted the steroidogenic sex hormones. It almost restored testosterone, FSH and LH serum levels to baseline. Similar findings were documented for TQ in an array of testicular toxicity models. TQ significantly attenuated cadmium- and lead-induced decreases in serum testosterone in rats (Fouad, Albuali, \& Jresat, 2014) and(Mabrouk \& Ben Cheikh, 2016).TQ ameliorated testicular tissue inflammation and restored the normal balance of sex hormones; testosterone, LH and FSH induced by sodium nitrite both in vivo and in vitro(Alyoussef \& Al-Gayyar, 2016).Aithal et al.(Aithal, Haseena, Das, \& Saheb, 2016) also showed that TQ increased the serum testosterone levels in arsenic-induced and sterptozotocine-induced testicular toxicity in male rats.

Capsaicin significantly increased the serum levels of testosterone, FSH and LH. Capsaicin appears to enhance testicular cell proliferation and can affect the release of ghrelin and testosterone directly or indirectly. It was also suggested that capsaicin-sensitive nerves contribute both to the regulation of blood content of dehydroepiandrosterone; testosterone precursor under normal and fructose-induced metabolic syndrome (Spiridonov, Tolochko, Ovsyukova, Kostina, \& Obut, 2017).

Also our results showed increase in FSH and LH levels in capsaicin $(10 \mathrm{mg} / \mathrm{kg})$ co- treated acrylamide groups compared to acrylamide alone $(35 \mathrm{mg} / \mathrm{kg})$ trteated groups and this agreed with the results ofErdost et al. (Erdost, Ozer, Yakisik, Ozfiliz, \& Zik, 2006) who pointed out that the number of FSH and LH immune-reactive cells increased in the unit area of the hypophysis when red hot pepper was added to chicken diets.

Acrylamide induced marked decrease in the testicular activity of LHD-X. LDH-X, a pachytene spermatocyte marker enzyme in the testis, is widely present in sertoli and spermatogenic cells, and plays an important role in testicular energy production and can be used as a marker in evaluating the function of spermatogenic cells. Odet et al. (Odet et al., 2011) hypothesized that in addition to its role in glycolysis, LDH-X is part of a complex involved in ATP homeostasis that is disrupted in sperms lacking LDH-X. LDH-X is a special enzyme produced at the phase of primary spermatogenic cells (Wu et al., 2017). The inhibition of LDH and LDH-X activities may induce denaturalization of spermatogenic cells (Ahmed, 2015). LDH-X has been suggested to be an index of testicular toxicity following exposure to different testicular toxicants (Adedara et al., 2017).

The correlation between disrupted LDH-X activity and sperm motility has been earlier studied by Odet $\boldsymbol{e t}$ $\boldsymbol{a l}$.(Odet et al., 2011).Abd-Ellah et al.(Abd-Ellah, Aly, Mokhlis, \& Abdel-Aziz, 2016) reported a positive correlation between LDH-X activity and sperm count. In addition, the study clarified that the decrease in testicular LDH-X activity in rat may be due to greater loss of germ cells from the testis, followed by 
their passage into epididymis. Decreased LDH-X level in the rats from Day 15 and Day 19 groups may be a consequence of enhanced lipid peroxidation after exposure to acrylamide, which may be due to fragmentation of the mitochondrial membrane ultra-structure that in turn affects the membrane bound LDH-X function.

In our recent experiment; pre-administration of TQ $(15 \mathrm{mg} / \mathrm{kg})$ before acrylamide $(35 \mathrm{mg} / \mathrm{kg})$ attenuated the acrylamide-induced decrease in the testicular LDH-X activity, Which come in parallel with Mabrouk et al . (Mabrouk, Salah, Chaieb, \& Cheikh, 2016) findings. Also our results show that co-administration of capsaicin $(10 \mathrm{mg} / \mathrm{kg})$ with acrylamide $(35 \mathrm{mg} / \mathrm{kg})$ attenuated acrylamide-induced decrease in the testicular LDH-X activity.

The finding in the current study that acrylamide induced oxidant stress in testicular tissue by increasing MDA and reducing GSH levels as well as the decreases in SOD and CAT activities may be one of the forerunners of such sperm morphological defects. The finding by Sun et al. (Sun, Wang, Gupta, \& Rosen, 2018)that exposure to acrylamide and its metabolite; glycidamide increased ROS level and decreased mitochondrial membrane potential, might lend support to this issue. Consistent with that was the finding byShi et al. (Shi et al., 2018) that the liberated lipid peroxides destroy the structure of lipid matrix in the membranes of spermatozoa leading to loss of motility and impairment of spermatogenesis and decreased sperm count.

Also, the administration of acrylamide resulted in significant elevation in testicular and epididymal MDA and significant reduction in the level of GSH and the activities of glutathione-S-transferase (GST), glutathione peroxidase (GPX) and glutathione reductase (GR) (Lebda, Gad, \& Gaafar, 2014). In a recent study conducted by Erdemli et al.(Erdemli et al., 2019), offspring male rats previously exposed in utero to acrylamide exhibited marked testicular oxidative stress as shown from the deterioration in the activities of CAT and SOD and the contents of GSH and MDA.

The protective effects of TQ on both spermatogenesis and steroidogenesis may reside at least in part on its antioxidant effects observed in the present work and elsewhere in a plethora of previous studies. In the current study, TQ significantly increased testicular GSH content and CAT and SOD activities while it reduced lipid peroxidation in testicular tissue. TQ significantly attenuated cadmium-induced decreases in serum testosterone, and testicular GSH and SOD activity and significantly decreased the elevation in testicular MDA (Fouad et al., 2014). TQ was also found to increase total anti-oxidant capacity with concomitant reduction in testicular lipid peroxidation following testis reperfusion injury in rats (Erol et al., 2017).

Javdan et al. (Javdan, Ayatollahi, Iqbal Choudhary, Al-Hasani, \& Pazoki-Toroudi, 2018)studied the role of capsaicin in tissue damage after testicular torsion. Testicular torsion-related oxidative stress causes a sequential chain of DNA damage, lipid peroxidation and cell death that leads to the derangement in the sperm functions and infertility. Capsaicin improved testicular morphology and decreased apoptosis in testes by targeting Forkhead Box O1 (FOXO1) gene and apoptotic pathways. Capsaicin attenuated spermatogenic cell death induced by scrotal hyperthermia through its antioxidative effects as shown by the diminished MDA level in testicular tissue (Park et al., 2017). Very recently, it was reported that combined treatment of capsaicin and curcumin improved significantly the oxidant/anti-oxidant status in male Sprague-Dawley rats fed a high fat diet. The combo increased significantly the activities of glutathione transferase, $\mathrm{Cu}-\mathrm{Zn}$ SOD, glutathione peroxidase and CAT, but decreased TBARS and ROS levels in liver and testicular tissues (Tanrıkulu-Küçük et al., 2019).

Immunohistochemical localization of NF- $x \mathrm{~B} / \mathrm{p} 65$ in testicular tissues after challenging animals with acrylamide revealed marked immunoreactivity for the protein denoting its marked translation in testicular tissue. This is the first finding to date that acrylamide would dramatically activate the NF- $\chi \mathrm{B} / \mathrm{p} 65$ pathway in testicular tissue. Nuclear factor-kappa B is a family of transcription factors implicated in numerous stress responses including apoptosis within male testicular cells (Baldwin Jr, 1996).Pentikainen et al. (Pentikäinen et al., 2002) demonstrated that under serum free conditions, an excessive amount of apoptotic activity was seen in human seminiferous tubules, concomitant with increased amounts of NF- $x \mathrm{~B}$ activity.

Another plausible mechanism for the toxic effects of acrylamide on spermatogenesis could be explained by virtue of its endocrine effects. As we know, FSH plays an important role in the process of spermatogenesis. 
Binding of FSH to its receptors on Sertoli cells leads to activation of adenylyl cyclase and subsequently the production of cAMP. Through this pathway, FSH indirectly leads to the activation of protein kinase A (PKA), which turns out to be a regulator of NF- $x$ B (KANGASNIEMI et al., 1990). Increased level of PKA causes an increase in NF- $\chi \mathrm{B}$ binding activity (Delfino \& Walker, 1998); the way in which PKA controls $\mathrm{NF}-\chi \mathrm{B}$ is through phosphorylation of $\mathrm{I} \chi \mathrm{B}$, which leads to its degradation (Ghosh \& Baltimore, 1990). So, by decreasing FSH production, acrylamide would probably inhibit the PKA-mediated degradation of NF- $\chi \mathrm{B}$, and this would ultimately lead to its superfluous localization in testicular tissue observed in the present work.

Interestingly, TQ notably decreased the expression of testicular NF- $\varkappa \mathrm{B} / \mathrm{p} 65$. Similar previous results were reported in other testicular toxicities. Fouad et al.(Fouad et al., 2014) have speculated that the protective effect of the TQ in arsenic-induced testicular injury in rats is ascribed to its modulatory effect on NF- $x \mathrm{~B}$. The downregulatory effects of $\mathrm{TQ}$ on $\mathrm{NF}-\varkappa \mathrm{B} / \mathrm{p} 65$ were also reported in an array of other toxidromes including cisplatin-induced nephropathy (Al-Malki \& Sayed, 2014), experimental diabetes (Usta \& Dede, 2017) and Freund's Complete Adjuvant-induced arthritis in rats (Arjumand, Shahzad, Shabbir, \& Yousaf, 2019).

Immunohistochemical localization of NF- $\chi \mathrm{B}$ revealed partial, albeit significant decrease in the expression of the inflammatory marker following capsaicin-acrylamide group compared to the animals that received acrylamide alone. Such finding is unique since no previous studies addressed this issue in testicular tissues before. Indeed, many other reports demonstrated the downregulatory effects of capsaicin on NF- $x \mathrm{~B}$ in other biological systems. Capsaicin is a quinone that has been shown to regulate a wide variety of activities that require NF-kappa B activation. An earlier study by Singh et al. (Singh, Natarajan, \& Aggarwal, 1996) examined the effect of capsaicin and its analogue, resiniferatoxin, on the activation of NF-kappa $B$ induced by different agents including TNF. Capsaicin treatment of cells blocked the degradation of I kappa B alpha, and thus the nuclear translocation of the p65 subunit of NF-kappa B, which is essential for NF-kappa B activation.

Of major interest in the current study was the finding that acrylamide perturbed the basement membrane of seminiferous tubules by downregulating occludin; one of its major junctional proteins. Occludin expresses in Sertoli cells, together with claudins, serving as a key component of tight junctions in the blood testes barrier (Morrow, Mruk, Cheng, \& Hess, 2010). It was found that the deletion or functional silencing of genes encoding tight junction proteins, to which belongs occludin, may disrupt the blood testes barrier (BTB), which may cause immunological or other damages to meiotic and postmeiotic cells and ultimately lead to spermatogenic arrest and infertility (Jiang et al., 2014).

Ablating occludin in vitro led to a quantitatively significant decrease in tight junctin function. Decreases in tight junction adhesiveness have also been observed when silencing occludin in keratinocytes (Rachow et al., 2013). Thus, recalling that acrylamide significantly decreased serum testosterone level might explain its downregulatory effect on the junctional protein in the basement membrane of seminiferous tubules.

The unique finding in the current study that TQ upregulated occludin in testicular tissue as shown from the increased immunofluorescent reactivity could possibly be explained by virtue of its downregulatory effect on NF- $x \mathrm{~B} / \mathrm{p} 65$. The earlier finding by Wachtel et al. (Wachtel et al., 2001) that the down-regulation of occludin expression in astrocytes by tumor necrosis factor (TNF) is mediated via TNF type-1 receptor and $\mathrm{NF}-\chi \mathrm{B} / \mathrm{p} 65$ activation might lend support to this view. This again would support the negative feedback of $\mathrm{NF}-x \mathrm{~B} / \mathrm{p} 65$ on the expression of the tight junction protein.

One of the outstanding results of the current study was the ability of capsaicin to upregulate the expression of the tight junctional protein; occludin in testicular tissue; to date, no similar results were reported. In a study conducted by Janyou et al.(Janyou et al., 2017), the authors investigated the effect of dihydrocapsaicin (DHC) on cerebral and blood brain barrier (BBB) damage in cerebral ischemia and reperfusion (I/R) models. Capsaicin increased the expression of tight junction proteins and significantly decreased oxidative stress and inflammation via down-regulation of reactive oxygen species (ROS), NADPH oxidase and NF- $x \mathrm{~B} / \mathrm{p} 65$.

The histopathological results in the present work confirmed the gained biochemical findings. The testicu- 
lar degeneration and inflammation associated with acrylamide treatment were greatly improved with TQ $(15 \mathrm{mg} / \mathrm{kg})$ and capsaicin intake $(10 \mathrm{mg} / \mathrm{kg})$ in comparison with acrylamide alone challenged group. acrylamide groups which are pretreated with TQ $(15 \mathrm{mg} / \mathrm{kg})$ and capsaicin $(10 \mathrm{mg} / \mathrm{kg})$ showed marked improvement in testicular tissue. Seminiferous tubules showed mild vacuolization in seminiferous epithelium and germ cell and slight inter-tubular edema and congestion compared to acrylamide alone $(35 \mathrm{mg} / \mathrm{kg})$ treated group which shows massive edema ,necrosis, vacuolation, degeneration of spermatogonial cells and severly congested blood vessels of seminiferous tubules. Yang et al. (Yang et al., 2005) reported that acrylamide induced histopathological lesions, such as formation of multinucleated giant cells and vacuolation associated with numerous apoptotic cells in seminiferous tubules, and such lesions appeared to increase Leydig cell death and perturb gene expression levels, contributing to sperm defects. Likewise, epididymal sperm reserves decreased significantly following oral exposure to acrylamide of weaned male Sprague-Dawley rats suggesting partial depletion of germ cells. In addition, histopathologic lesions were also present in the testes of treated rats (Wang et al., 2010).Tüfek et al.(Tüfek, Altunkaynak, Altunkaynak, \& Kaplan, 2015) demonstrated beneficial effects of TQ on mean volumes of testes and seminiferous tubules, the number of spermatogenic cells and also Leydig cells in rats following feeding a high-fat diet. Also, the improvement of histopathological abnormalities produced by pretreatment of acrylamide by capsaicin is in accordance with the results of Sarioglu-Buke et al.(Sarioglu-Buke, Erdem, Gedikoglu, Bingol-Kologlu, \& Tanyel, 2001)

\section{Conclusion}

Based on these broad observations, one could argue that both nutraceuticals tested in the current study have improved the spermatogenic and steroidogenic functions in male rats. Though one cannot unravel the exact mechanism(s) whereby both natural drugs have exerted their beneficial actions, however their anti-oxidant and anti-inflammatory effects observed in the present work maybe one of the culprits behind this issue. Besides, their unique up-regulatory effects on occludin expression in testicular tissue could possibly account to their protective effects on gonadal tissue as they restored the integrity of the basement membrane whose complex network structure compiles many of the junctional proteins and adherence molecules and other adaptor proteins. So, by restoring the tight junction integrity the blood testes barrier acts once again as a defense mechanism against various xenobiotics such as acrylamide.

\section{Conflict of interest}

None.

\section{Funding}

None.

\section{Author contributions}

Ekram Nemr Abd Al Haleem developed the research idea, designed the experiments, supervised the experiment execution and wrote the manuscript; Walaa Yousef Soliman Hasan performed the experiments, collected the data, analyzed the data, and performed the graphical and statistical analysis. Hossam El-Deen Mohamed Mohamed Arafa suggests the research idea, supervised the experiments execution, supervised the data analysis and revised the manuscript. All authors have approved the article for submission and they certify that this article has been subjected to professional language editing.

\section{Acknowledgement}

Authors acknowledge Dr. Kawkab A Ahmed, Professor of pathology, Faculty of Veterinary Medicine, Cairo University for her help in the histopathological and immnohistochemical examinations part in this work.

\section{References}

Abd-Ellah, M., Aly, H., Mokhlis, H., \& Abdel-Aziz, A. (2016). Quercetin attenuates di-(2-ethylhexyl) phthalate-induced testicular toxicity in adult rats. Human 83 experimental toxicology, 35 (3), 232-243. 
Abdel-Fattah, A.-F. M., Matsumoto, K., \& Watanabe, H. (2000). Antinociceptive effects of Nigella sativa oil and its major component, thymoquinone, in mice. European journal of pharmacology, 400 (1), 89-97.

Adedara, I. A., Olabiyi, B. F., Ojuade, T. D., Idris, U. F., Onibiyo, E. M., \& Farombi, E. O. (2017). Taurine reverses sodium fluoride-mediated increase in inflammation, caspase-3 activity, and oxidative damage along the brain-pituitary-gonadal axis in male rats. Canadian journal of physiology and pharmacology, 95 (9), 1019-1029.

Ahmed, M. A. (2015). Amelioration of nandrolone decanoate-induced testicular and sperm toxicity in rats by taurine: effects on steroidogenesis, redox and inflammatory cascades, and intrinsic apoptotic pathway. Toxicology and applied pharmacology, 282 (3), 285-296.

Aithal, M., Haseena, S., Das, K. K., \& Saheb, S. H. (2016). Effect of Nigella Sativa seed and Thymoquinone on Reproductive Parameters in Sterptozotocine Induced Diabetic and Normal Male Albino Rats. Int J Intg Med Sci, 3 (3), 248-252.

Al-Malki, A. L., \& Sayed, A. A. R. (2014). Thymoquinone attenuates cisplatin-induced hepatotoxicity via nuclear factor kappa- $\beta$. BMC complementary and alternative medicine, 14 (1), 282.

Alyoussef, A., \& Al-Gayyar, M. M. (2016). Thymoquinone ameliorated elevated inflammatory cytokines in testicular tissue and sex hormones imbalance induced by oral chronic toxicity with sodium nitrite. Cytokine, $83,64-74$.

Aras, D., Cakar, Z., Ozkavukcu, S., Can, A., \& Cinar, O. (2017). In Vivo acrylamide exposure may cause severe toxicity to mouse oocytes through its metabolite glycidamide.PloS one, 12 (2), e0172026.

Arjumand, S., Shahzad, M., Shabbir, A., \& Yousaf, M. Z. (2019). Thymoquinone attenuates rheumatoid arthritis by downregulating TLR2, TLR4, TNF- $\alpha$, IL-1, and NF $\varkappa$ B expression levels. Biomedicine $\&$ Pharmacotherapy, 111 , 958-963.

Atta, M. S., El-Far, A. H., Farrag, F. A., Abdel-Daim, M. M., Al Jaouni, S. K., \& Mousa, S. A. (2018). Thymoquinone attenuates cardiomyopathy in streptozotocin-treated diabetic rats. Oxidative medicine and cellular longevity, 2018 .

B Aggarwal, B., Prasad, S., Reuter, S., Kannappan, R., R Yadav, V., Park, B., .. Sundaram, C. (2011). Identification of novel anti-inflammatory agents from Ayurvedic medicine for prevention of chronic diseases: "reverse pharmacology" and "bedside to bench" approach. Current drug targets, 12 (11), 1595-1653.

Baldwin Jr, A. S. (1996). The NF- $x \mathrm{~B}$ and I $\chi \mathrm{B}$ proteins: new discoveries and insights. Annual review of immunology, 14 (1), 649-681.

Banchrof, J., Steven, A., \& Turner, D. (1996). Theory and practice of histopathological techniques. In: Churchil Livingstone, New York, London, San Francisco, Tokyo.

Bratthauer, G. L. (2010). The avidin-biotin complex (ABC) method and other avidin-biotin binding methods. In Immunocytochemical methods and protocols, (pp. 257-270): Springer.

Cheever, K. L., Weigel, W. W., Richards, D. E., Lal, J. B., \& Plotnick, H. B. (1985). Testicular effects of bis (2-methoxyethyl) ether in the adult male rat. Toxicology and industrial health, 5 (6), 1099-1109.

Chhabra, N., Aseri, M., Goyal, V., \& Sankhla, S. (2012). Capsaicin: A promising therapy-A critical reappraisal. International Journal of Nutrition, Pharmacology, Neurological Diseases, 2 (1), 8.

Delfino, F., \& Walker, W. H. (1998). Stage-specific nuclear expression of NF- $x \mathrm{~B}$ in mammalian testis.Molecular endocrinology, 12 (11), 1696-1707.

Ellman, G. L. (1959). Tissue sulfhydryl groups. Archives of biochemistry and biophysics, 82 (1), 70-77.

Erdemli, Z., Erdemli, M. E., Turkoz, Y., Gul, M., Yigitcan, B., \& Gozukara Bag, H. (2019). The effects of acrylamide and Vitamin E administration during pregnancy on adult rats testis. Andrologia, e13292. 
Erdost, H., Ozer, A., Yakisik, M., Ozfiliz, N., \& Zik, B. (2006). FSH and LH cells in the laying hens and cocks, fed with a diet containing red hot pepper. JOURNAL OF FOOD AGRICULTURE AND ENVIRONMENT, $4(1), 119$.

Erol, B., Sari, U., Amasyali, A., Ozkanli, S., Sogut, S., Hanci, V., ... Yencilek, F. (2017). Comparison of combined antioxidants and thymoquinone in the prevention of testis ischemia-reperfusion injury. Andrology, 5 (1), 119-124.

Foster, P. M., Blackburn, D. M., Moore, R. B., \& Lloyd, S. C. (1986). Testicular toxicity of 2methoxyacetaldehyde, a possible metabolite of ethylene glycol monomethyl ether, in the rat. Toxicology letters, 32 (1-2), 73-80.

Fouad, A. A., Albuali, W. H., \& Jresat, I. (2014). Protective effect of thymoquinone against arsenic-induced testicular toxicity in rats. In Kuala Lumpur, Malaysia: International Conference on Pharmacology and Pharmaceutical Medicine (ICPPM) (Vol. 8): Citeseer.

Freund, M., \& Carol, B. (1964). Factors affecting haemocytometer counts of sperm concentration in human semen. Reproduction, 8 (2), 149-155.

Friedman, M. (2003). Chemistry, biochemistry, and safety of acrylamide. A review. Journal of agricultural and food chemistry, 51 (16), 4504-4526.

Ghosh, S., \& Baltimore, D. (1990). Activation in vitro of NF- $\varkappa$ B" by phosphorylation of its inhibitor I $\mathrm{B}^{\prime \prime}$. Nature, 344 (6267), 678.

Greenwald, R. (1985). CRC Handbook of Methods for Oxygen Radical. by Thornalley PJ, Bannister JV, CRC Press, New York, 133-136.

He, Y., Tan, D., Mi, Y., Bai, B., Jiang, D., Zhou, X., \& Ji, S. (2017). Effect of epigallocatechin-3-gallate on acrylamide-induced oxidative stress and apoptosis in PC12 cells. Human 8 experimental toxicology, 36 (10), 1087-1099.

Hoppe, P. C., \& Pitts, S. (1973). Fertilization in vitro and development of mouse ova. Biology of reproduction, $8(4), 420-426$.

Hosseinzadeh, H., \& Parvardeh, S. (2004). Anticonvulsant effects of thymoquinone, the major constituent of Nigella sativa seeds, in mice. Phytomedicine, 11 (1), 56-64.

Janyou, A., Wicha, P., Jittiwat, J., Suksamrarn, A., Tocharus, C., \& Tocharus, J. (2017). Dihydrocapsaicin attenuates blood brain barrier and cerebral damage in focal cerebral ischemia/reperfusion via oxidative stress and inflammatory.Scientific reports, 7 (1), 10556.

Javdan, N., Ayatollahi, S., Iqbal Choudhary, M., Al-Hasani, S., \& Pazoki-Toroudi, H. (2018). FOXO 1 targeting by capsaicin reduces tissue damage after testicular torsion.Andrologia, 50 (4), e12987.

Jiang, X.-H., Bukhari, I., Zheng, W., Yin, S., Wang, Z., Cooke, H. J., \& Shi, Q.-H. (2014). Blood-testis barrier and spermatogenesis: lessons from genetically-modified mice.Asian journal of andrology, 16 (4), 572.

KANGASNIEMI, M., KAIPIA, A., TOPPARI, J., PERHEENTUPA, A., HUHTANIEMI, I., \& PARVINEN, M. (1990). Cellular regulation of follicle-stimulating hormone (FSH) binding in rat seminiferous tubules. Journal of andrology, 11 (4), 336-343.

Kuorwel, K., Lumori, C., \& Andrew, A. (2018). Review of South Sudans Food Safety Status in Relation to Chemical Contaminants. MOJ Food Process Technol, 6 (1), 00153.

Lebda, M., Gad, S., \& Gaafar, H. (2014). Effects of lipoic acid on acrylamide induced testicular damage.Materia socio-medica, 26 (3), 208.

Mabrouk, A., \& Ben Cheikh, H. (2016). Thymoquinone supplementation ameliorates lead-induced testis function impairment in adult rats. Toxicology and industrial health, 32 (6), 1114-1121. 
Mabrouk, A., Salah, I. B. H., Chaieb, W., \& Cheikh, H. B. (2016). Protective effect of thymoquinone against lead-induced hepatic toxicity in rats. Environmental Science and Pollution Research, 23 (12), 12206-12215.

Markkula, M., Hämäläinen, T., Loune, E., \& Huhtaniemi, I. (1995). The follicle-stimulating hormone (FSH) beta-and common alpha-subunits are expressed in mouse testis, as determined in wild-type mice and those transgenic for the FSH beta-subunit/herpes simplex virus thymidine kinase fusion gene.Endocrinology, 136 (11), 4769-4775.

Marklund, S. L. (1985). Product of extracellular-superoxide dismutase catalysis. FEBS letters, 184 (2), 237-239.

Morrow, C. M., Mruk, D., Cheng, C. Y., \& Hess, R. A. (2010). Claudin and occludin expression and function in the seminiferous epithelium. Philosophical Transactions of the Royal Society B: Biological Sciences, 365 (1546), 1679-1696.

Mu, Y., Yan, W.-j., Yin, T.-l., Zhang, Y., Li, J., \& Yang, J. (2017). Diet-induced obesity impairs spermatogenesis: a potential role for autophagy. Scientific reports, 7 , 43475.

O'Neill, J., Brock, C., Olesen, A. E., Andresen, T., Nilsson, M., \& Dickenson, A. H. (2012). Unravelling the mystery of capsaicin: a tool to understand and treat pain.Pharmacological reviews, 64 (4), 939-971.

O'Donnell, L., Meachem, S., Stanton, P., \& McLachlan, R. (2006). Endocrine regulation of spermatogenesis. In 'Physiology of Reproduction. Vol. 1'. 3rd edn.(Ed. JD Neill.) pp. 1017-1069. In: Elsevier: Amsterdam.

Odell, I. D., \& Cook, D. (2013). Immunofluorescence techniques. The Journal of investigative dermatology, 133 (1), e4.

Odet, F., Gabel, S. A., Williams, J., London, R. E., Goldberg, E., \& Eddy, E. M. (2011). Lactate dehydrogenase $\mathrm{C}$ and energy metabolism in mouse sperm. Biology of reproduction, 85 (3), 556-564.

Ozer, A., Zik, B., Erdost, H., \& OZFILIZ, N. (2006). Histological investigations on the effects of feeding with a diet containing red hot pepper on the reproductive system organs of the cock. Turkish Journal of Veterinary and Animal Sciences, 30 (1), 7-15.

Pakarainen, T., Ahtiainen, P., Zhang, F.-P., Rulli, S., Poutanen, M., \& Huhtaniemi, I. (2007). Extragonadal LH/hCG action - not yet time to rewrite textbooks. Molecular and cellular endocrinology, 269 (1-2), 9-16.

Park, S., Yon, J. M., Lin, C., Gwon, L., Lee, J. G., Baek, I. J., .. Nam, S. Y. (2017). Capsaicin attenuates spermatogenic cell death induced by scrotal hyperthermia through its antioxidative and antiapoptotic activities.Andrologia, 49 (5), e12656.

Parvez, S., Malik, K. A., Ah Kang, S., \& Kim, H. Y. (2006). Probiotics and their fermented food products are beneficial for health. Journal of applied microbiology, 100 (6), 1171-1185.

Parzefall, W. (2008). Minireview on the toxicity of dietary acrylamide. Food and Chemical Toxicology, 46 (4), 1360-1364.

Pentikäinen, V., Suomalainen, L., Erkkilä, K., Martelin, E., Parvinen, M., Pentikäinen, M. O., \& Dunkel, L. (2002). Nuclear factor- $\chi \mathrm{B}$ activation in human testicular apoptosis. The American journal of pathology, 160 (1), 205-218.

Pourentezari, M., Talebi, A., Abbasi, A., Khalili, M. A., Mangoli, E., \& Anvari, M. (2014). Effects of acrylamide on sperm parameters, chromatin quality, and the level of blood testosterone in mice. Iranian journal of reproductive medicine, 12 (5), 335.

Pyun, C. W., Kim, J. H., Han, K. H., Hong, G. E., \& Lee, C. H. (2014). In vivo protective effects of dietary curcumin and capsaicin against alcohol-induced oxidative stress.BioFactors, 40 (5), 494-500. 
Rachow, S., Zorn-Kruppa, M., Ohnemus, U., Kirschner, N., Vidal-y-Sy, S., von den Driesch, P., .. Vettorazzi, E. (2013). Occludin is involved in adhesion, apoptosis, differentiation and Ca2+-homeostasis of human keratinocytes: implications for tumorigenesis. PloS one, 8 (2), e55116.

Ramaswamy, S., \& Weinbauer, G. F. (2014). Endocrine control of spermatogenesis: Role of FSH and LH/testosterone. Spermatogenesis, 4 (2), e996025.

Salahshoor, M. R., Haghjoo, M., Roshankhah, S., Makalani, F., \& Jalili, C. (2018). Effect of thymoquinone on reproductive parameter in morphine-treated male mice.Advanced biomedical research, 7 .

Sarioglu-Buke, A., Erdem, S., Gedikoglu, G., Bingol-Kologlu, M., \& Tanyel, F. (2001). Capsaicin effectively prevents apoptosis in the contralateral testis after ipsilateral testicular torsion. BJU international, 88 (7), 787-789.

Sayed, M. M., Hassanein, K. M., \& Senosy, W. (2014). Protective effects of thymoquinone and l-cysteine on cadmium-induced reproductive toxicity in rats. Toxicology reports, 1 , 612-620.

Shi, L., Zhou, T., Huang, Q., Zhang, S., Li, W., Zhang, L., .. Pazour, G. J. (2018). Intraflagellar transport protein 74 is essential for mouse spermatogenesis and male fertility by regulating axonemal microtubule assembly in mice.bioRxiv , 457804 .

Shimeda, Y., Hirotani, Y., Akimoto, Y., Shindou, K., Ijiri, Y., Nishihori, T., \& Tanaka, K. (2005). Protective effects of capsaicin against cisplatin-induced nephrotoxicity in rats. Biological and Pharmaceutical Bulletin, 28 (9), 1635-1638.

Singh, S., Natarajan, K., \& Aggarwal, B. B. (1996). Capsaicin (8-methyl-N-vanillyl-6-nonenamide) is a potent inhibitor of nuclear transcription factor-kappa B activation by diverse agents. The Journal of Immunology, 157 (10), 4412-4420.

Slone, E. J., Teuschler, L. K., Aume, L. L., Narotsky, M. G., Simmons, J. E., Lordo, R. A., \& Rice, G. E. (2012). Estimation of individual rodent water consumption from group consumption data for gestation, lactation, and postweaning life stages using linear regression models. ILAR journal, 53 (1), E99-E112.

Spiridonov, V., Tolochko, Z., Ovsyukova, M., Kostina, N., \& Obut, T. (2017). The Role of CapsaicinSensitive Nerves in Regulating Blood Dehydroepiandrosterone Sulfate Levels in Rats in Normal Conditions and in Metabolic Syndrome.Neuroscience and Behavioral Physiology, 47 (1), 33-39.

Sun, N., Wang, Y., Gupta, S. K., \& Rosen, C. J. (2018). Nitrogen Fertility and Cultivar Effects on Potato Agronomic Properties and Acrylamide-forming Potential. Agronomy Journal .

Tanrıkulu-Küçük, S., Başaran-Küçükgergin, C., Söğüt, İ., Tunçdemir, M., Doğru-Abbasoğlu, S., Seyithanoğlu, M., ... Öner-İyidoğan, Y. (2019). Dietary curcumin and capsaicin: Relationship with hepatic oxidative stress and apoptosis in rats fed a high fat diet. Advances in clinical and experimental medicine: official organ Wroclaw Medical University .

Tareke, E., Rydberg, P., Karlsson, P., Eriksson, S., \& Törnqvist, M. (2002). Analysis of acrylamide, a carcinogen formed in heated foodstuffs. Journal of agricultural and food chemistry, 50 (17), 4998-5006.

Tavakkoli, A., Ahmadi, A., Razavi, B. M., \& Hosseinzadeh, H. (2017). Black seed (Nigella sativa) and its constituent thymoquinone as an antidote or a protective agent against natural or chemical toxicities. Iranian journal of pharmaceutical research: IJPR, 16 (Suppl), 2.

Tietz, N. (1986). In; Text book of clinical chemistry, Edited by NW Tietz. In: WB Saunders company, Philadelphia, London, Toronto.

Tüfek, N. H., Altunkaynak, M. E., Altunkaynak, B. Z., \& Kaplan, S. (2015). Effects of thymoquinone on testicular structure and sperm production in male obese rats.Systems biology in reproductive medicine, 61 (4), 194-204. 
Tyl, R. W., \& Friedman, M. A. (2003). Effects of acrylamide on rodent reproductive performance.Reproductive Toxicology, 17 (1), 1-13.

Uchiyama, M., \& Mihara, M. (1978). Determination of malonaldehyde precursor in tissues by thiobarbituric acid test. Analytical biochemistry, 86 (1), 271-278.

Usta, A., \& Dede, S. (2017). The effect of thymoquinone on nuclear factor kappa B levels and oxidative DNA damage on experimental diabetic rats. Pharmacognosy magazine, 13 (Suppl 3), S458.

Wachtel, M., Bolliger, M. F., Ishihara, H., Frei, K., Bluethmann, H., \& Gloor, S. M. (2001). Down-regulation of occludin expression in astrocytes by tumour necrosis factor (TNF) is mediated via TNF type-1 receptor and nuclear factor- $x \mathrm{~B}$ activation. Journal of neurochemistry, 78 (1), 155-162.

Wang, H., Huang, P., Lie, T., Li, J., Hutz, R. J., Li, K., \& Shi, F. (2010). Reproductive toxicity of acrylamide-treated male rats. Reproductive Toxicology, 29 (2), 225-230.

Wu, S., Ren, X., Li, Y., Guo, W., Lei, X., Yao, J., \& Yang, X. (2017). Effect of dietary Astragalus Polysaccharide supplements on testicular miRNA expression profiles and enzymatic changes of breeder cocks. Scientific reports, 7,38864 .

Wyrobek, A. J., Gordon, L. A., Burkhart, J. G., Francis, M. W., Kapp Jr, R. W., Letz, G., .. Whorton, M. D. (1983). An evaluation of the mouse sperm morphology test and other sperm tests in nonhuman mammals: A report of the US Environmental Protection Agency Gene-Tox Program. Mutation Research/Reviews in Genetic Toxicology, 115 (1), 1-72.

Xiao, Y., Nabi, G., Yang, J., Hao, Y., \& Wang, D. (2018). Hormonal Regulation of Testicular Development in the Finless Porpoise Neophocaena asiaeorientalis sunameri: Preliminary Evidence from Testicular Histology and Immunohistochemistry.Zoological Studies, 57, 1-13.

Xie, S., Li, G., Qu, L., Zhong, R., Chen, P., Lu, Z., .. Ma, A. (2017). Podophyllotoxin extracted from Juniperus sabina fruit inhibits rat sperm maturation and fertility by promoting epididymal epithelial cell apoptosis. Evidence-Based Complementary and Alternative Medicine, 2017.

Yadav, S. K., PATIL, S., \& Gupta, S. (2013). Nutraceutical-A bright scope and opportunity of Indian healthcare market. International Journal of Research and Development in Pharmacy and Life Sciences, 2 (4), 478-481.

Yang, H.-J., Lee, S.-H., Jin, Y., Choi, J.-H., Han, D.-U., Chae, C., .. Han, C.-H. (2005). Toxicological effects of acrylamide on rat testicular gene expression profile. Reproductive Toxicology, 19 (4), 527-534.

Zhang, L., Xu, Y., Li, Y., Bao, T., Gowd, V., \& Chen, W. (2017). Protective property of mulberry digest against oxidative stress-A potential approach to ameliorate dietary acrylamide-induced cytotoxicity. Food chemistry, 230 , 306-315.

Figures legends

Figure (1): Effects of thymoquinone or capsaicin on the percentage change in testicular lactate dehydrogenase isoenzyme-X (LDH-X) activity of acrylamide-challenged male Swiss albino rats

Data are expressed as means $\pm \mathrm{SEM},(\mathrm{n}=10)$.

$\mathrm{a}$, b or c Significant difference from control or acrylamide or TQ plus acrylamide groups, respectively at $\mathrm{p}$ $<0.05$ using one way ANOVA followed by Tukey post-hoc test for multiple comparisons.

Figure (2): Photomicrographs of testicular tissue specimens stained by H \& E (X400).

(A) Transverse testicular section from control group showing normal histological structure of the mature active seminiferous tubules with complete spermatogenic series in the tubular lumen (S).(B) Transverse testicular section of testis from TQ-treated group showing intact histological structure of the seminiferous tubules with complete spermatogenic series. (C) Transverse testicular section of testis from capsaicin-treated 
group showing intact histological structure of the seminiferous tubules with complete spermatogenic series. (D) Transverse testicular section from acrylamide-treated group showing severe degeneration and necrosis of primary, secondary and spermatid cells lining seminiferous tubule (large arrow), vacuolation of primary spermatocytes lining seminiferous tubules is also noticed (arrow head ). (E) Transverse testicular section from acrylamide-treated group showing vascular changes including interstitial edema (large arrow) and focal hemorrhage (arrow head). Interstitial Leydig cells show pyknosis (star) while spermatogoneal cells lining seminiferous tubules undergo desquamation (double arrow) were also noticed. (F) Transverse testicular section from acrylamide-treated rats showing degenerated necrotic spermatogoneal cells lining seminiferous tubule (small arrow) as well as interstitial edema (large arrow) and vacuolation of Leydig interstitial cells (arrow head). (G) Transverse testicular section from the group that received TQ plus acrylamide showing intact histological structure with complete spermatogenesis in most of the seminiferous tubules. $(\mathbf{H})$ Transverse testicular section from rats co-administered TQ and acrylamide showing congestion of blood vessels in some few seminiferous tubules (large arrow) and pyknosis in the nuclei of some spermatogonial cells (small arrow). (I) Transverse testicular section from animals concurrently treated with capsaicin and acrylamide showing normal intact histological structure of the seminiferous tubules with complete spermatogenic series in the lumen. (G) Transverse testicular section from rats treated with a combination of capsaicin and acrylamide showing few seminiferous with interstitial edema (arrows) and vacuolation of leydig interstitial cells (heads of arrows).

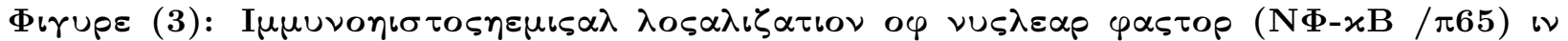 $\tau \varepsilon \sigma \tau \iota \varsigma U \lambda \alpha \rho \tau \iota \sigma \sigma \cup \varepsilon$.}

Photomicrograph of transverse section of rat; showing expression of NF- $\chi \mathrm{B} / \mathrm{p} 65$ in testicular tissue by immunohistochemical staining (X 400). (A)Immunohistochemical staining of NF- $x \mathrm{~B} / \mathrm{p} 65$ in rat testicular tissue section from control group showing no apparent expression (negative immunoreactivity). (B) Immunohistochemical staining of $\mathrm{NF}-\varkappa \mathrm{B} / \mathrm{p} 65$ in rat testicular tissue section from TQ group showing no apparent expression (negative immunoreactivity). (C) Immunohistochemical staining of $\mathrm{NF}-\varkappa \mathrm{B} / \mathrm{p} 65$ in rat testicular tissue section from capsaicin group showing no expression (negative immunoreactivity). (D) Immunohistochemical staining of NF- $x \mathrm{~B} / \mathrm{p} 65$ in rat testicular tissue section from acrylamide group showing over-expression (strong positive immunoreactivity; brown color denoted by black arrow). (E) Immunohistochemical staining of NF- $\varkappa \mathrm{B} / \mathrm{p} 65$ in rat testicular tissue section from TQ plus acrylamide group showing mild expression (weak positive immunoreactivity; brown color denoted by black arrow). (F) Immunohistochemical staining of $\mathrm{NF}-x \mathrm{~B} / \mathrm{p} 65$ in rat testicular tissue section from capsaicin plus acrylamide group showing mild expression (weak positive immunoreactivity; brown color denoted by black arrow).

\section{Figure (4): Immunoflorescence detection of occludin in testicular tissue.}

Photomicrograph of transverse section of rat showing immunoflorescence detection of occludin in testicular tissue (X 20). (A)Immunofluorescent staining of occludin in rat testicular section from control group showing normal nuclei (stars) stained blue (DAPI), and normal interstitial expression and distribution of occludin (green fluorescence; Cruz Fluor 488) (arrows). (B) Immunofluorescent staining of occludin in rat testicular section from TQ-treated group showing normal nuclei (stars) stained blue (DAPI), and normal interstitial expression and distribution of occludin (green fluorescence; Cruz Fluor 488) (arrows). (C) Immunofluorescent staining of occludin in rat testicular section from capsaicin-treated group showing normal nuclei (stars) stained blue (DAPI), and normal interstitial expression and distribution of occludin (green fluorescence; Cruz Fluor 488) (arrows). (D) Immunofluorescent staining of occludin in rat testicular section from acrylamide-challenged group showing abnormal expression and distribution of occludin interstitially (arrows) (lower interstitial fluorescent green color intenisty) and also abnormal nuclear (stars) distribution (higher nuclear fluorescent green color intenisty). (E)Immunofluorescent staining of occludin in rat testicular section from acrylamide-challenged group that concomitantly received TQ. The section depicts restoration of the expression of occludin interstitially (as marked by higher green fluorescence (arrows) than nuclear expression (stars). (F) Immunofluorescent staining of occludin in rat testicular tissue from acrylamide-challenged group that concurrently received capsaicin. The section shows increased interstitial green fluorescence inten- 
sity and distribution of occludin (arrows) higher than nuclear distribution and expression of the junctional protein (stars).

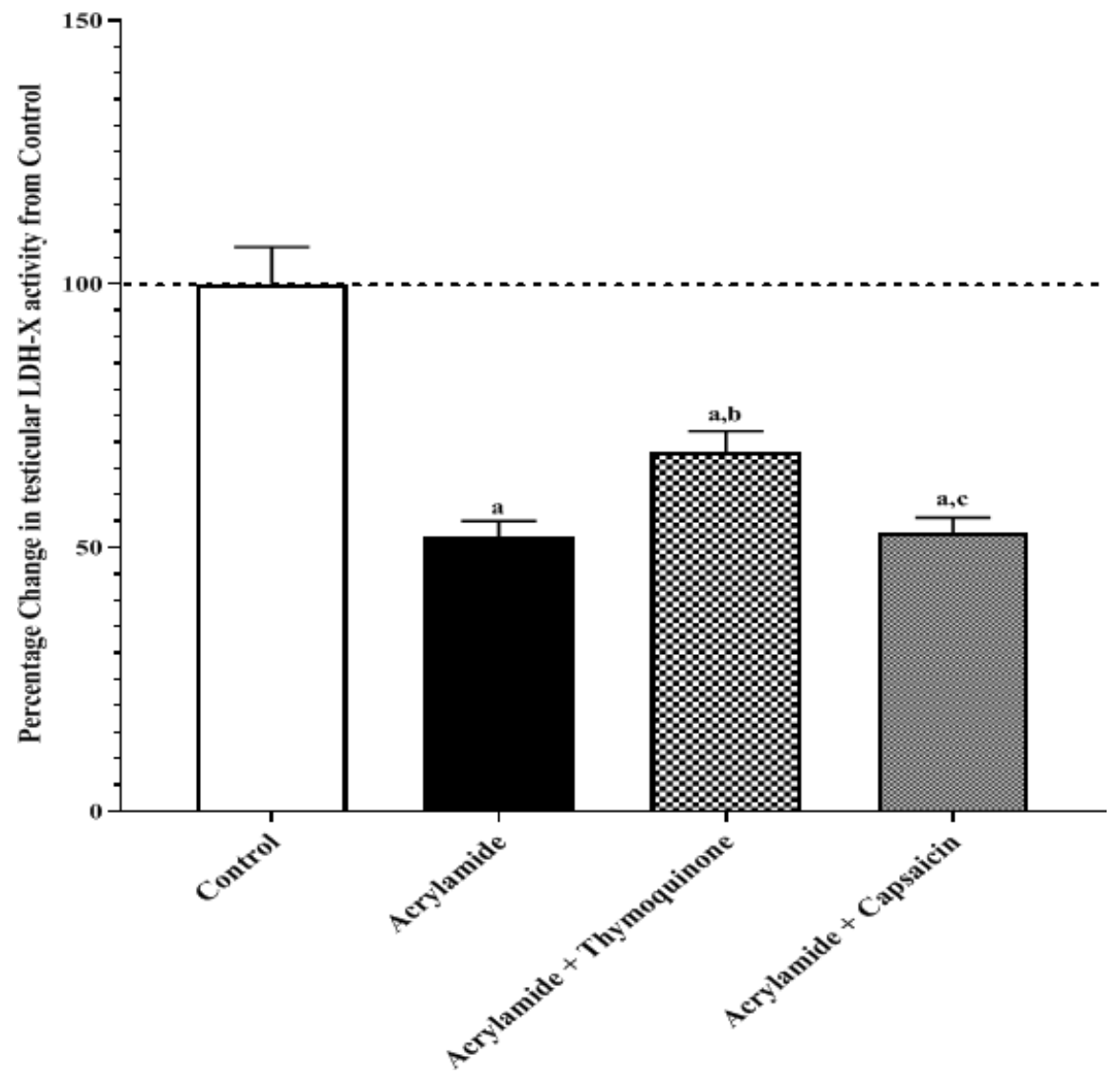




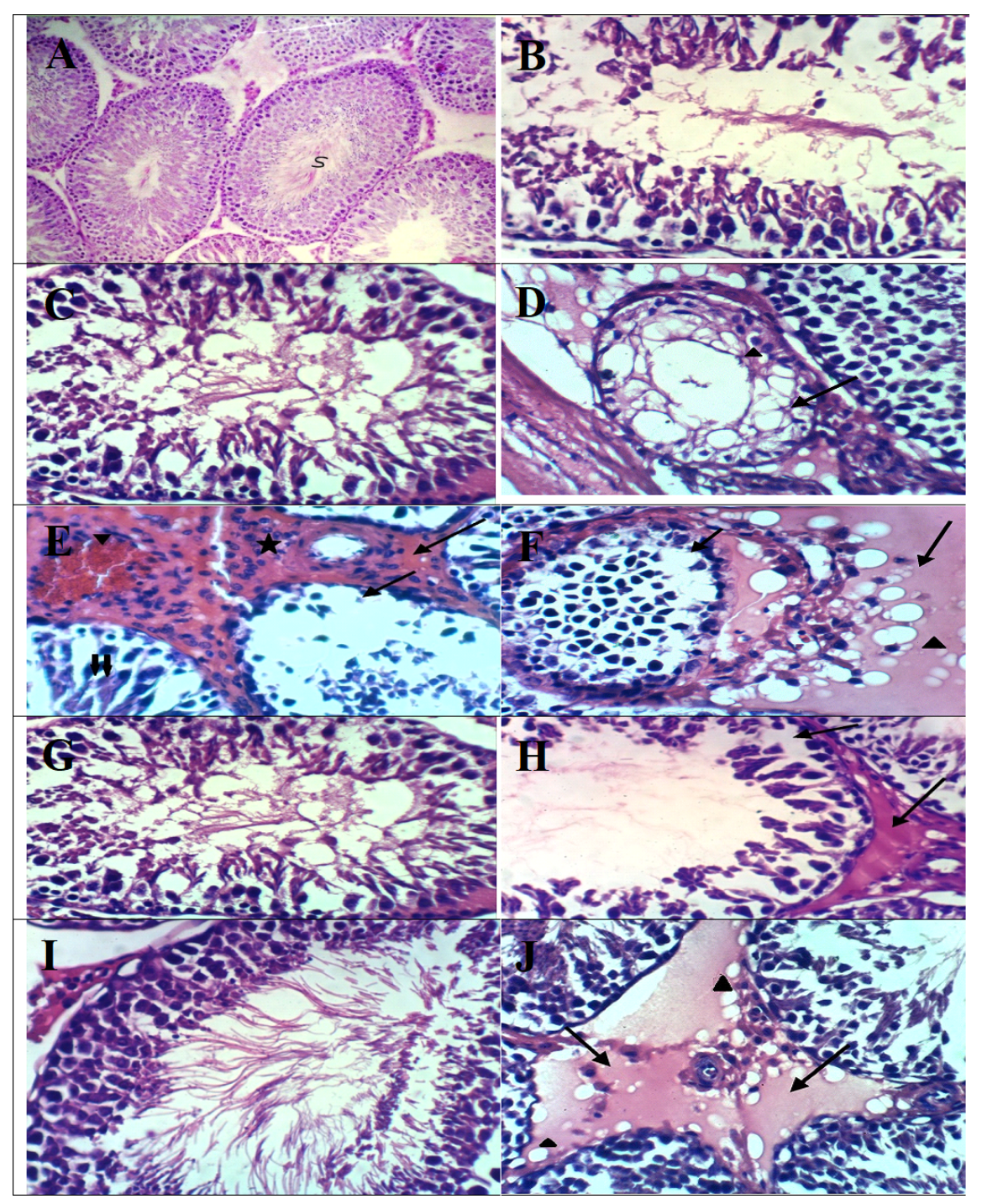




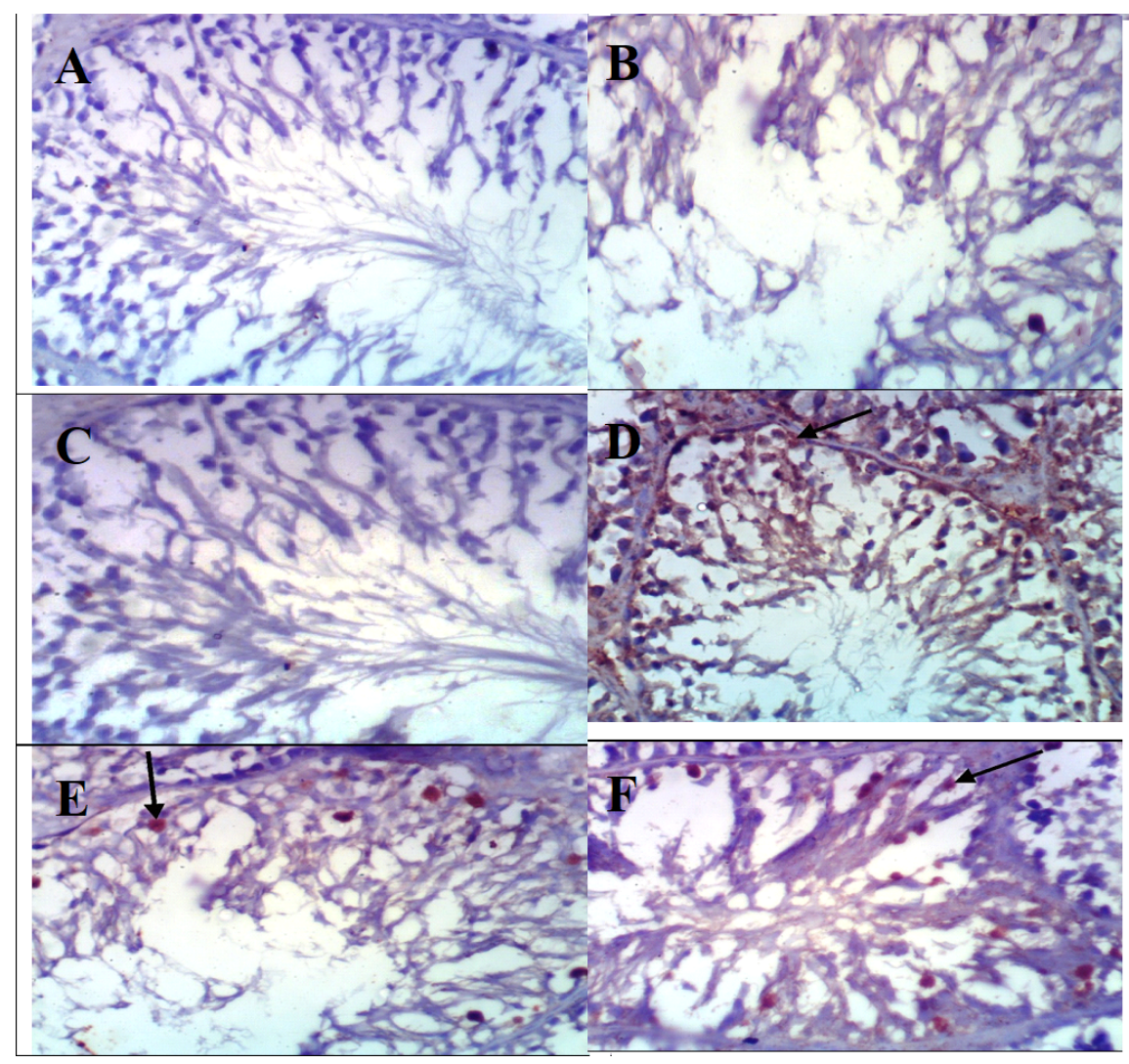




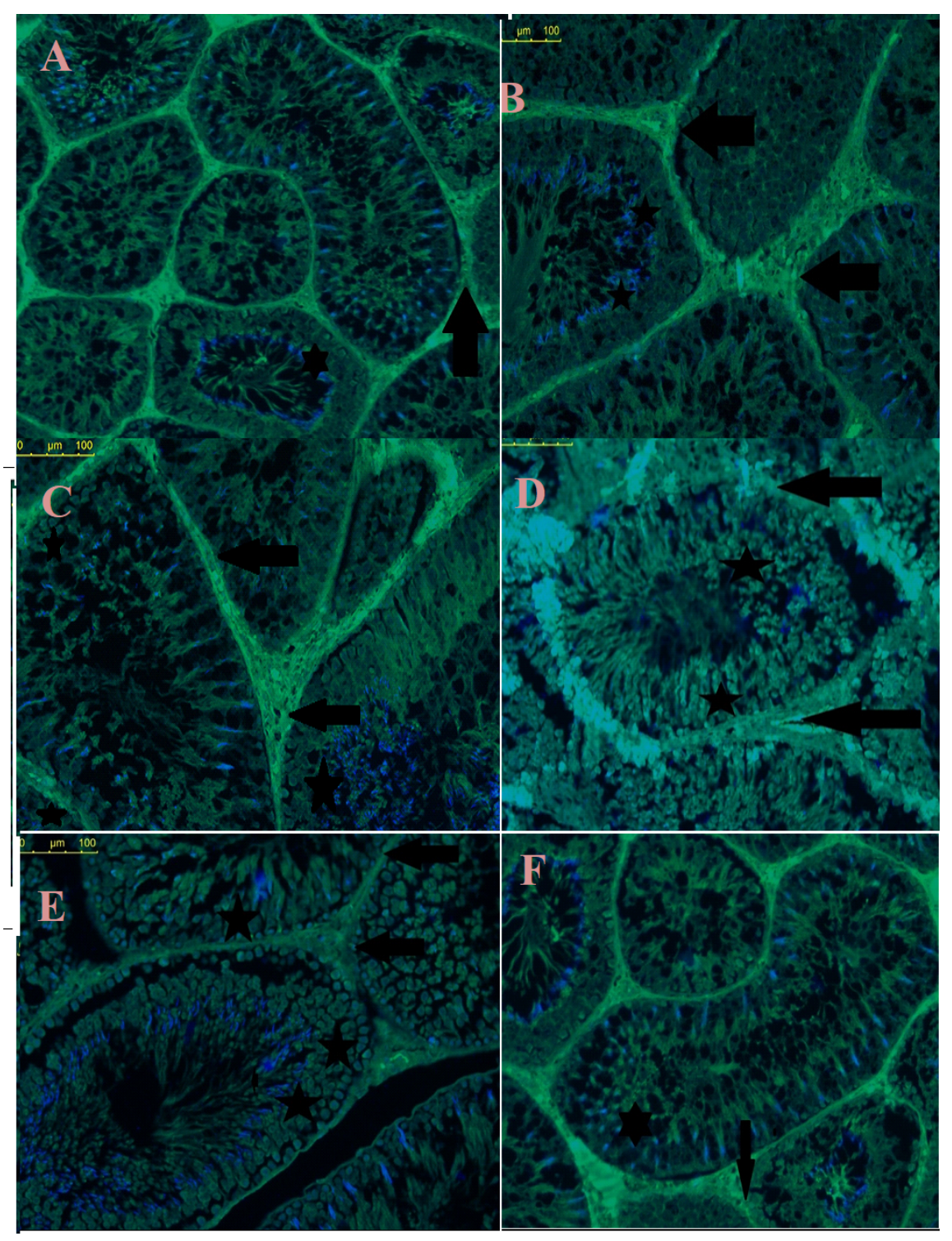

\section{Hosted file}

tables.docx available at https://authorea.com/users/355015/articles/478437-effects-ofthymoquinone-or-capsaicin-against-acrylamide-induced-testicular-failure-in-rats-impactoxidative-stress-nf-\%CE\%BAb-p65-and-occludin 